Original Research Paper

\title{
Passive Approach for Fault Tolerant Controller Using Hybrid Controller Structure for Effective Level Control of Conical Tank System
}

\author{
Himanshukumar R. Patel and Vipul A. Shah \\ Department of Instrumentation and Control, Dharmsinh Desai University, Nadiad, India
}

Article history

Received: 22-12-2018

Revised: 22-08-2019

Accepted: 02-09-2019

Corresponding Author: Himanshukumar R. Patel

Department of Instrumentation and Control, Dharmsinh Desai University, Nadiad, India

Email: himanshupatelp32@gmail.com

\begin{abstract}
The Article Propose An Efficacious Fault Tolerant Control (FTC) Strategy Using The Hybrid Controller Structure To Establish Stable And Tracking Control With Two Faults Constrain In The Area Of Two Tank Canonical Non-Interacting Level Control System (TTCNILCS). Many Process Industries Use Canonical Tanks Because Of Its Varying Cross-Section Area Which Contributes Better Throughput From An Outlet For Different Material. Hence TTCNILCS Exhibit Nonlinear Behavior Because Of Its Changing Cross Section Area. The Problem Of Passive FTC (PFTC) For The TTCNILCS With The Unknown Actuator And Sensor Fault Is Investigated. The Actuator And Sensor Fault Is Assumed To Have No Traditional Affine Appearance Of The System And Control Input. Hybrid Controller (Neural Network Plus PID Controller) Is Used To Design PFTC And Implement To Achieve Satisfactory Steady-State Performance From TTCNILCS. The Effectiveness Of The Proposed Controller Validate From The Simulation Results And Errors Like MSE, ISE And ITAE.
\end{abstract}

Keywords: Actuator Fault, Conical Tank System, Hybrid Controller, Passive Fault Tolernat Control, Sensor Fault

\section{Introduction}

In modern chemical, petrochemical and food process industries, Safety and cost-effective functioning of the these plants depends among other parameters, on controller designs that account for essentially nonlinearity of the complex processes, operative issue, constraints (i.e., system, actuator and sensor faults) and uncertainties (i.e., process disturbances), as well as an abnormality in the processes (Patel and Shah, 2019a). The sequential and interconnected nature of chemical processes sets a more prominence on handling these issues to avoid breeding of the faults and causing unexpected plant downtime or safety risk (Patel and Shah, 2018c). These examinations prompt development of control scheme that take care for nonlinearities, uncertainty, constraints as well as are tolerant capability to faults (fault-tolerant control). Past twenty years the Faulttolerant control has been an active area of research and has inspire many research work in the context of safetycritical engineering applications like complex chemical process, nuclear power plant, aerospace application etc. illustrated in (Patel and Shah, 2018c; Du, 2012;
Villani et al., 2010; Jiang and Zhang, 2003; Isermann and Balle, 1997; Wayne and Bequette, 1991).

For implementing the fault-tolerant control two possibilities are there one is implement some hardware redundancy (i.e., sets of the sensor/actuator or combination of that can be used to implement controllers) and second option is analytical redundancy (i.e., software control implementation), that can either be used all at one time or activated when the some abnormality occurs in the system (Isermann and Balle, 1997). The FTC basically classified into two category, one is Passive FTC and second is Active FTC (Patel and Shah, 2018a; Jiang and Yu, 2012). The main objectives of both strategy is same but only the structure of the controller is different, both have its own advantages and disadvantages (Patel and Shah, 2018a; 2018d). From past two decade significant research has been done for an improved control performance of single-tank (noninteracting) and multi-tank (interacting) system with fault or without fault constraints. Intelligent control approach becoming more popular compared to conventional control scheme due to effectiveness and robust behaviour (Patel and Shah, 2020; 2019c; "in 
press Patel and Shah, 2019d; "in press Patel and Shah, 2019e). Type-1 fuzzy logic controller implemented for three-tank system and found robust behaviour under different condition of disturbances (Maruthai et al., 2009). In (Shamily et al., 2015) comparative study carried out between adaptive controller, Neuro controller and PID controller for interactive three-tank system from observing the results adaptive and neuro controller gives superior performance. In (Parikh et al., 2017) author proposed Linear Quadratic Gaussian Control (LQG) and compared with the Non-linear Model Predictive Control (NMPC) to achieve the servo plus disturbance rejection and regulatory control of a three tank level control system in presence of varying dynamics of the system.

To maintain safety and profitable operation in any engineering system under different fault conditions FaultTolerant Control (FTC) become more popular and some FTC applications and trends is inspected in (Patel and Shah, 2019a; 2018d; Frank, 2004). To take advantages of human/operator knowledge FTC framework proposed and applied on interactive and non-interactive system using artificial intelligence (neural network) under two fault and process disturbances (Patel and Shah, 2018d). In (Basin et al., 2015) author has proposed finite-time convergent fault-tolerant algorithm and an experimental validation of FTC is conducted for a DTS200 three-tank system through changing fault sources, process disturbances, input conditions and disturbances through inter-tank connections. Distributed FTC and a flatness based approach of FTC designed and implemented in (Torres et al., 2013; Capiluppi and Paoli, 2005) for threetank and two-tank level control system respectively, subsequently in (Altinisik and Yildirim, 2012) author designed FTC using data mining approach for three-tank level control system with fault. In (Buciakowski et al., 2014; Noura et al., 2000) FTC designed and applied to the three-tank system and quadruple tank system with actuator fault respectively. The author of (Patel and Shah, 2018b) designed FTC using fuzzy logic and conventional PI controller and reported good control performance in simulation platform with system fault and undefined process disturbance. Thereafter in "in press (Patel and Shah, 2019b)" author validate the proposed FTC strategy from implemented on experimental single-tank noninteracting system with system component (leak) fault.

Controlling any process broadly categorize into two subjects, regulatory and tracking control. In regulatory control the prime objective of the controller is to maintain the reference input which is ideally predefined and constant. In the contradictory tracking control's objective is to make the output follow a reference input. Regulatory controllers' performance is determined via good stability margin, not having steady state error, good disturbance and noise rejection and low output's variance. In this paper Two-Tank Canonical NonInteracting Level Control System (TTCNILCS) is examine to be controlled. The TTCNILCS laboratory model can be viewed as a prototype of many industrial applications in process industry, such as chemical and petrochemical plants, oil and gas systems. The classic control issue elaborate in the system is how to keep the desired liquid level in tank 2 with system component and actuator fault. The prototype structure of the TTCNILCS is shown in Fig. 1 (Patel and Shah, 2019a).

Two Tank Canonical Non-Interacting Level Control System (TTCNILCS) is one of the supremely nonlinear, complex and unstable systems by nature. It is generally used as a test bench to develop advanced control algorithms for different nonlinear system model as well as for experimental and educational studies of nonlinear control system.

This paper proposes Passive FTC strategy using Neural Network plus conventional PI controller which fulfills the most of the control requirements very effectively for the TTCNILCS as mentioned below:

- Stabilizing control under two fault and different magnitude conditions of tank 2 level is obtained with low transient and without any steady state problem.

- Tracking control with variable step change trajectories is achieved in spite of fault and unknown process disturbances.

Organization of work flow is as follows: Section-II, describes the modeling of TTCNILCS. In section-III, conventional PID controller design. In section-IV, design of PFTC controller is explained and compare with PID controller response and encountered problems are discussed. In, section-V, The flow meter will need to create these components, incorporating the applicable criteria that follow. Simulation results are presented to validate the effectiveness of proposed research work followed by the conclusion.

\section{Mathematical Modeling for TTCNILCS}

\section{Process Description}

In TTCNILCS, the process accommodate two identical conical shape tanks in the sequential manner shown in Fig. 1. (Patel and Shah, 2019a); the one identical pumps deliver the liquid inflow Fin and one outlet flow $F_{\text {out }}$ in tank 1 , the outlet flow $F_{\text {out }}$ of tank 1 is subsequently inlet flow of tank 2 and outlet flow is $F_{o}$ respectively through the two control valves $V_{1}$ and $V_{2}$. The two tanks under consideration should have the same cross-sectional area. The main objective in mathematical modeling is to find the transfer function for the system that is a relation between output variable $h_{2}(s)$ (liquid height in Tank 2) and input variable $F_{\text {in }}(s)$ (Inlet flow to tank 1). In this case, the manipulated variable is $F_{\text {in }}(s)$ and controlled variable is $h_{2}(s)$. 


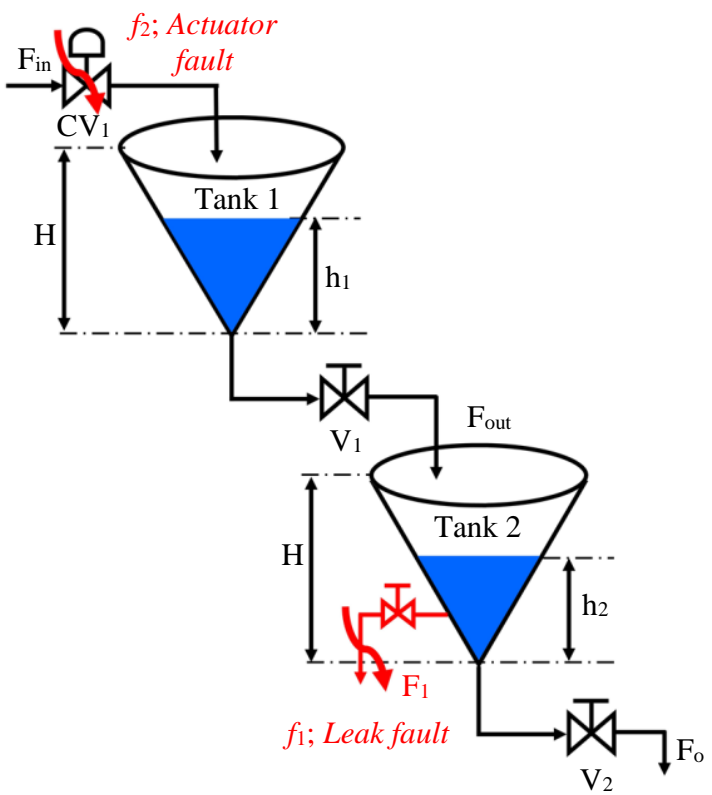

Fig. 1: Prototype structure of Two-Tank Canonical NonInteracting Level Control System (TTCNILCS) (Patel and Shah, 2019a)

\section{Mathematical Modeling of TTCNILCS}

Prototype model of TTCNILCS is shown in Fig. 1. (Patel and Shah, 2019a), where the inlet flow rate $\left(F_{\text {in }}\right)$ which is manipulated variable to control the controlled variable tank 2 height $\left(h_{2}\right)$ via proposed hybrid controller. In the given system two control valve $\left(V_{1}\right)$ and $\left(V_{2}\right)$ provides constant flow rate and third control valve $\left(C V_{1}\right)$ manipulating $\left(F_{i n}\right)$ and archiving the controlled variable $\left(h_{2}\right)$ via proposed controller. Parameters of prototype structure are mentioned in Table 1.

Mathematical equation of the liquid tank system is derived using the Total Mass Balance Equation. According to that principle described in (Patel and Shah, 2019a; Wayne and Bequette, 2003):

\section{Rate of Accumulation $=$ inflow - outflow}

The mathematical equation is derived for both the conical tanks separately as follows. From Fig. 2. Single conical tank system is given and can be written as following equation:

$$
A=\pi r^{2}
$$

From the Fig. 1:

$\tan \theta=\frac{R}{H}$

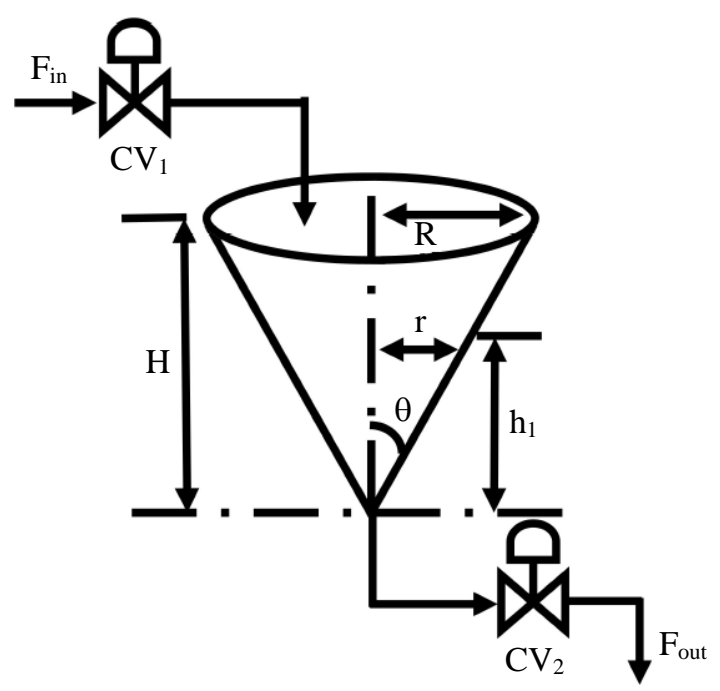

Fig. 2: Single conical tank (Patel and Shah, 2019a)

Table 1: Physical parameters of TTCNILCS

\begin{tabular}{lll}
\hline Parameter & Symbol & Value \\
\hline Total Height of the tank & $\mathrm{H}$ & $60 \mathrm{~cm}$ \\
Top Radius of the Tank & $\mathrm{R}$ & $15 \mathrm{~cm}$ \\
$M V_{1}$ Valve Co-efficient & $\beta_{1}$ & $5 \mathrm{~cm}^{2} / \mathrm{sec}$ \\
$M V_{2}$ Valve Co-efficient & $\beta_{2}$ & $2 \mathrm{~cm}^{2} / \mathrm{sec}$ \\
Gravitational constant & $\mathrm{g}$ & $9.82 \mathrm{~m} / \mathrm{sec}^{2}$ \\
Actuator fault coefficient & $\alpha$ & $0-30 \%$ \\
System Component fault & $F_{1}$ & $0-30 \%$ \\
\hline
\end{tabular}

At any height $\left(h_{1}\right)$ of Tank 1:

$\tan \theta=\frac{r}{h_{1}}=\frac{R}{H}$

Simplified mass balance equation for tank 1 of TTCNILCS can be written by (1) as per (Patel and Shah, 2019a; Isermann and Balle, 1997):

$\frac{d h_{1}}{d t}=\frac{\left[F_{i n}-\frac{1}{3} h_{1} \frac{d A\left(h_{1}\right)}{d t}-\beta_{1} \sqrt{2 g h_{1}}\right]}{\left(\frac{1}{3} \pi R^{2} \frac{h_{1}^{2}}{H^{2}}\right)}$

Area of the canonical Tank 1 at height $\left(h_{1}\right)$ and Tank 2 at any height $\left(h_{2}\right)$ :

$A_{1}=\frac{\pi R^{2} h_{1}^{2}}{H^{2}}, A_{2}=\frac{\pi R^{2} h_{2}^{2}}{H^{2}}$

Similarly, for Tank 2 the mass balance equation is given by following relation (Patel and Shah, 2019a; Isermann and Balle, 1997): 


$$
\frac{d h_{2}}{d t}=\frac{\left[\beta_{1} \sqrt{2 g h_{1}}-\frac{1}{3} h_{2} \frac{d A\left(h_{2}\right)}{d t}-\beta_{2} \sqrt{2 g h_{2}}\right]}{\left(\frac{1}{3} \pi R^{2} \frac{h_{2}^{2}}{H^{2}}\right)}
$$

where, outlet flow of Tank 1 and Tank 2 given by:

$$
F_{\text {out }}=\beta_{1} \sqrt{2 g h_{1}}, F_{o}=\beta_{2} \sqrt{2 g h_{2}}
$$

Now, mathematical model of TTCNILCS with actuator and system component (leak) faults given as follows (Patel and Shah, 2019a):

$$
\begin{aligned}
& \frac{d h_{1}}{d t}=\frac{\left[\alpha_{1} F_{i n}-\frac{1}{3} h_{1} \frac{d A\left(h_{1}\right)}{d t}-\beta_{1} \sqrt{2 g h_{1}}\right]}{\left(\frac{1}{3} \pi R^{2} \frac{h_{1}^{2}}{H^{2}}\right)} \\
& \frac{d h_{2}}{d t}=\frac{\left[\alpha_{1} \beta_{1} \sqrt{2 g h_{1}}-\frac{1}{3} h_{2} \frac{d A\left(h_{2}\right)}{d t}-\beta_{2} \sqrt{2 g h_{2}}-F_{1}\right]}{\left(\frac{1}{3} \pi R^{2} \frac{h_{2}^{2}}{H^{2}}\right)}
\end{aligned}
$$

where, $\alpha_{1}$ denotes actuator fault and $F_{1}$ denotes system component (leak) fault.

For the simplification take both the tank identical in size so area of both the tank is same. Combining (1) and (2) would give the nonlinear transfer function of TTCNILCS (6):

$$
G_{P}=\frac{K_{1} K_{1}}{\left(\tau_{1} s+1\right)\left(\tau_{2} s+1\right)} e^{-t_{d} s}
$$

By taking the prototype model parameters, the transfer function of the proposed system is demonstrate as follows:

$$
G_{P}=\frac{1.2393}{44038.51 s^{2}+1135.1 s+1}
$$

With considering of the transportation delay in the TTCNILCS the model of the system given as follows:

$$
G_{P}=\frac{1.2393}{44038.51 s^{2}+1135.1 s+1} e^{-t_{d} s}
$$

Adding the transportation delay in the system adding constrain in the system like instability and sluggish response. Once the transfer function is obtained, then the controller can be designed for the conical tank process.

\section{PID Controller Design}

The conventional Proportional-Integral-Derivative (PID) controller used in this paper is demonstrate by (9):

$u=K_{P}\left(e(t)+K_{i} \int e(t) d t+K_{d} \frac{d e(t)}{d t}\right)$

The above structure of PID controller after simplifications in the Laplace domain is presented by (10):

$G_{C}(s)=\frac{\left(K_{P} K_{d}\right) s^{2}+\left(K_{P}\right) s+\left(K_{P} K_{i}\right)}{s}$

Simplified TTCNILCS structure based on (7) can be written by (11):

$G(s)=\frac{b_{0}}{s^{2}+a_{1}+a_{0}}$

Characteristics equation for overall unity feedback control system of TTCNILCS can be expressed by (12):

$s^{3}+\left(a_{1}+b_{0} K_{P} K_{d}\right) s^{2}+\left(a_{0}+b_{0} K_{P}\right) s+b_{0} K_{P} K_{i}=0$

As discussed in (Dorf and Bishop, 2011), optimum third ordered characteristics equation based on ITAE criterion with step input can be expressed by (13):

$s^{3}+\left(1.75 W_{n}\right) s^{2}+\left(2.15 W_{n}\right) s+W_{n}^{3}=0$

Selecting $W_{n}$ which is moderately higher than the value of the natural frequency of complex conjugate pole which is at $\mathrm{S}=+49.55$, as used in (Tian, 2015). Comparing (12) and (13) with $W_{n}$, PID controller gains can be founded as follows:

$$
K_{P}=32.0531 ; K_{d}=1.7921 ; K_{i}=7.9581
$$

\section{PFTC Strategy Using Hybrid Controller}

This section presents the control solution of the problems using conventional PID controllers plus Neural Network for TTCNILCS as mentioned in results. To perform an effective control for stable, tracking and disturbance rejection problems, hybrid controller is used to designed and implemented for the application of TTCNILCS which is termed as a PFTC in this paper. Basic structure of the proposed PFTC strategy is shown by Fig. 3. The ideology of a passive FTCS is to find a controller wihin the region of interaction among all admissible solution sets which can give the robust control structure. As appere, in Fig. 4, this region equivalent to the darken area where the permissible solution sets intersects. 


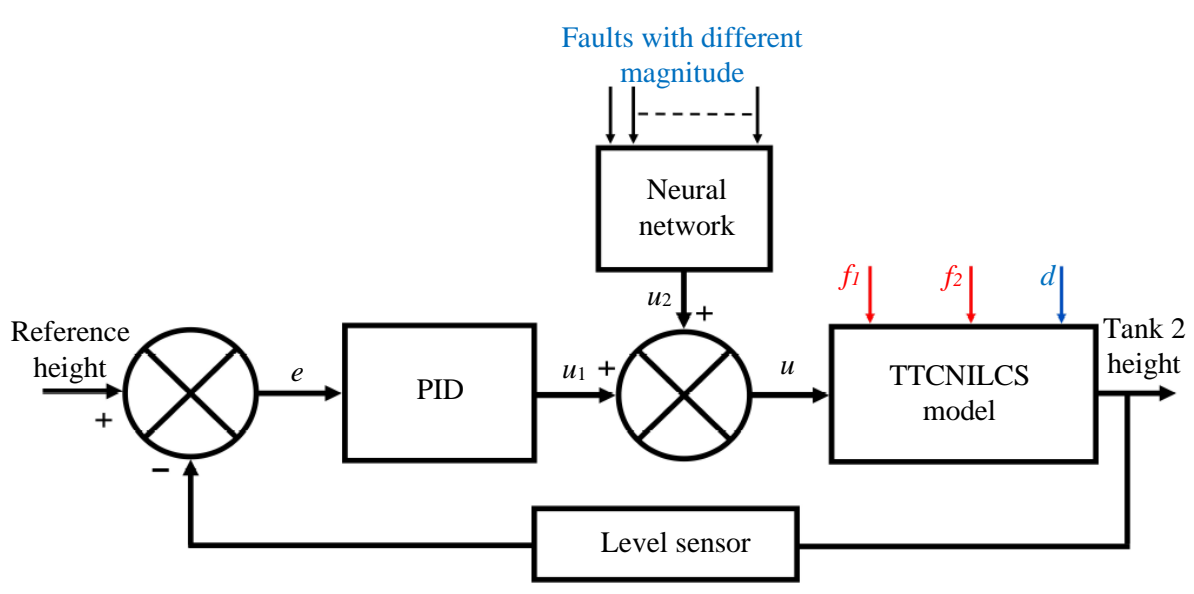

Fig. 3: Structure of PFTC using hybrid controller

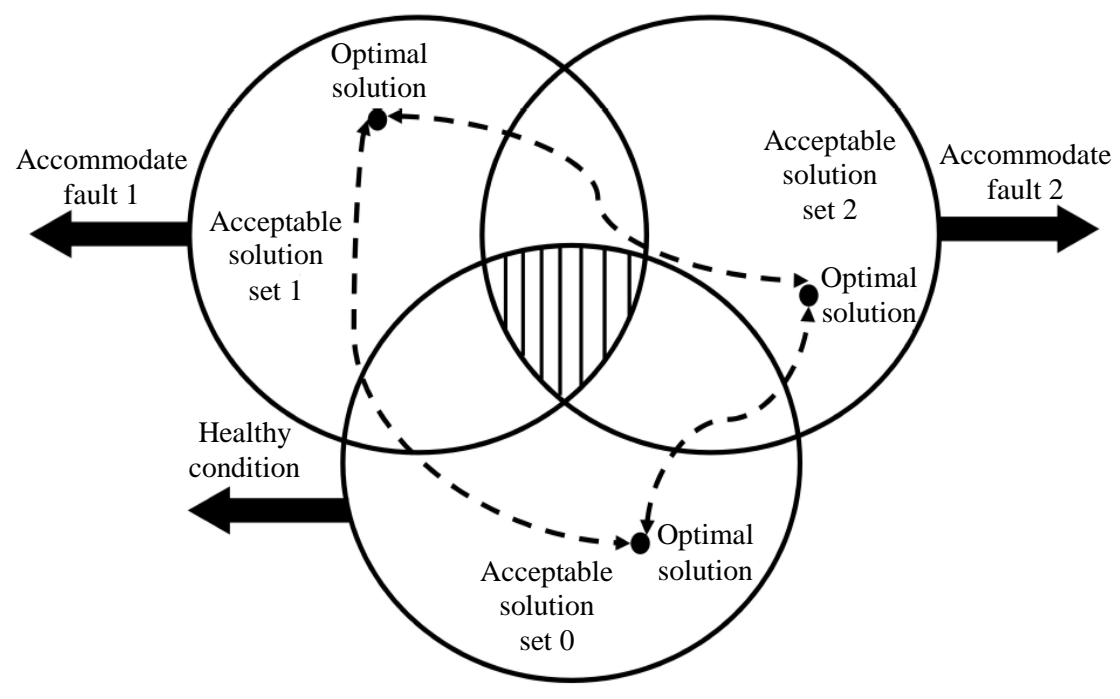

Fig. 4: Tolerable solution space for PFTC

\section{Possible Solution of PFTC Design with Two Fault}

An ideology of a PFTC is to realize an acceptable controller within the region of convergence among all admissible solution sets. As presented in Fig. 2, this region corresponds to the shadowed area where the admissible solution sets intersect. Some restricted situations in a PFTC amalgam are shown in four subplots in Fig. 5 where no single overlap can be found. Sacrifices may have to be made even for the normal system operating conditions to accommodate expected failure cases. As shown in Fig. 5a, no PFTC can be found to deal with the normal condition.

Also the other permissible solution set of PFTC illustrated in Fig. 5b and 5c, in which the one fault occurs in the system at a time either system fault $f_{1}$ and actuator fault $f_{2}$.
From performance perspective, a passive FTCS focuses more on the robustness of the control system to accommodate multiple faults without attempting for optimal performance for any particular fault condition. Since the stability is the number one consideration in a passive approach, the designed controller turns to be more traditional from performance perspective. If there is an overlap among all the permissible solution sets for considered fault cases, a single controller can theoretically deal with any presumed design basis faults. Although, nothing can be said about the behavior of the system when a failures beyond design basis occur. Also the types and magnitude of the different faults are play significant role at designed level, the designed PFTC only for system and actuator fault with some predetermined fault magnitude beyond that the performance and stability of the system is degrade. 


\section{Consider Fault Scenarios for TTCNILCS}

The paper deals with, the system (leak) fault which represent situations where the tank 2 level reduce significantly and manipulated variable $\left(F_{i} n\right)$ not coup to maintaining the tank 2 level efficiently hence control performance is degrade. In TTCNILCS, actuator fault considered as a second fault. Which leads in the situation where the final control element $\left(C V_{1}\right)$ is not opening properly according to controller signal and it gives lesser manipulated variable $\left(F_{\text {in }}\right)$ compare to actual. These circumstances lead to performance deteriorate.

\section{Simulation Results}

For evaluating PFTCS, two design basis fault cases have been chosen as shown in Table 2. As appear in Fig. 6 and Fig. 7, the proposed PFTC regulatory response is presentd for system leak and actuator fault respectively. As depicted in the response figure, the same magnitude of actuator fault is more vital as compared to the system leak fault. The error results are tabulated in Table 3 and 4 for the system leak and actuator fault respectively. The servo responses are also carried out for the proposed PFTCS scheme on TTCNILCS with and without design basis faults. To evaluate the servo response two different trajectory is taken one is variable step and sinusoidal. Fig. 8 displayed the servo response for the PFTCS without fault and Fig. 9 and Fig. 10 displayed the servo response for the PFTCS with system leak and actuator fault respectively. The same way sinusoidal trajectory given as a reference signal and found the PFTCS responses with and without faults which are represented in Figs. 11, 12 and 13. To check the robustness of the design PFTCS, the design basis two faults and process distrubances are introduced into TTCNILCS simentously or at the same time. The responses of PFTCS are displayed in Fig. 14 with four subfigure. The error results are tabulated in Table 5.

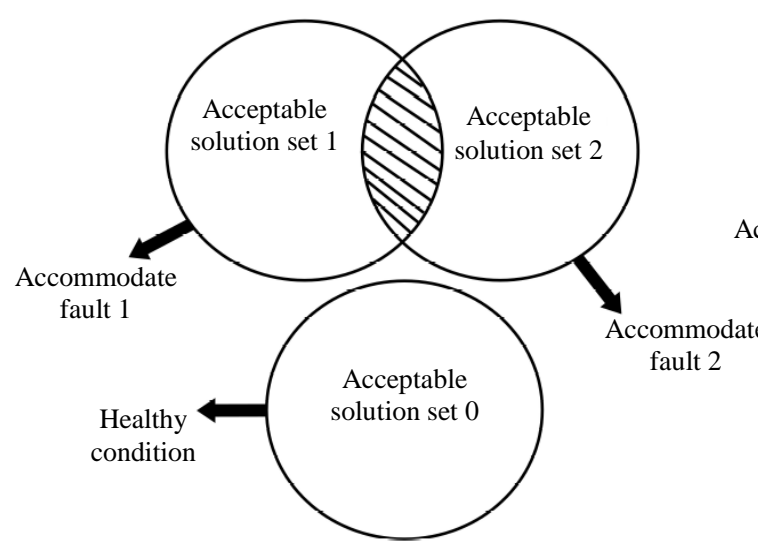

(a)

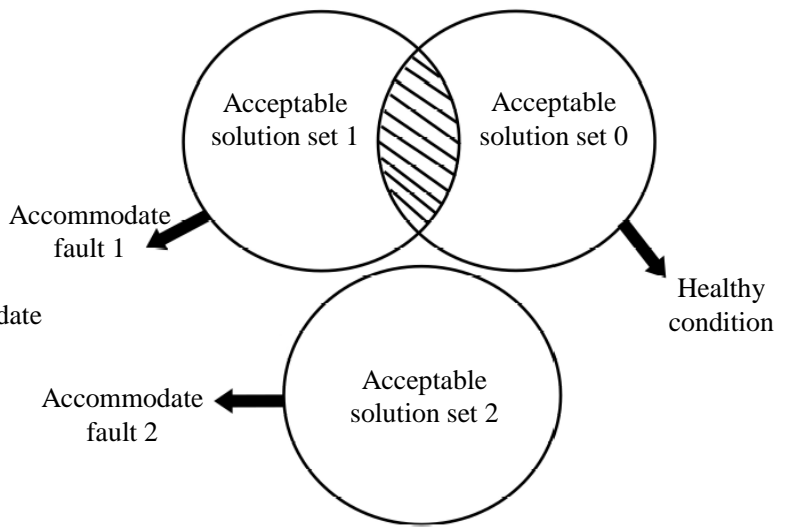

(b)

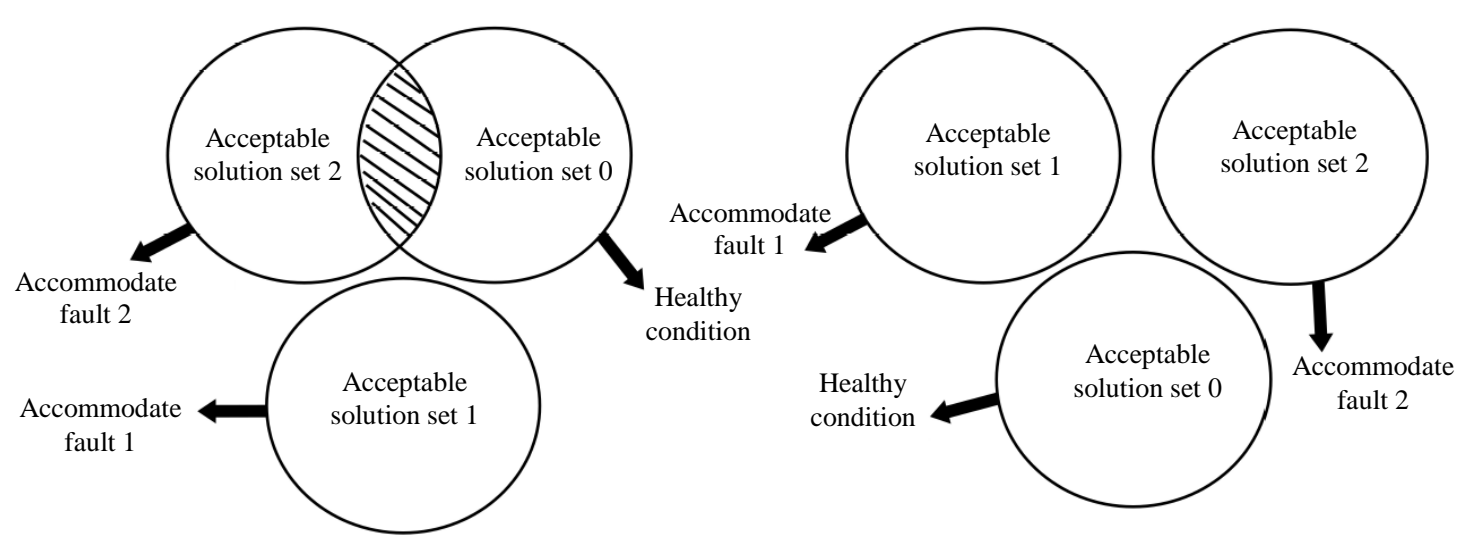

(c)

(d) 


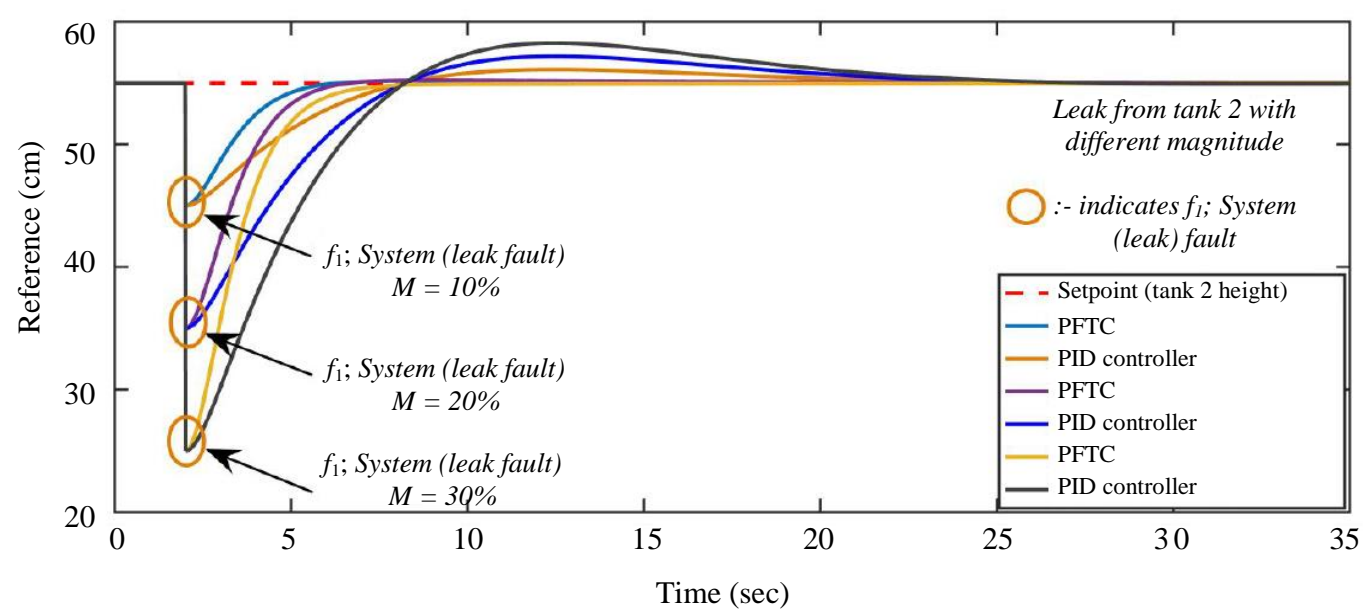

Fig. 6: TTCNILCS height response with different magnitude of system fault

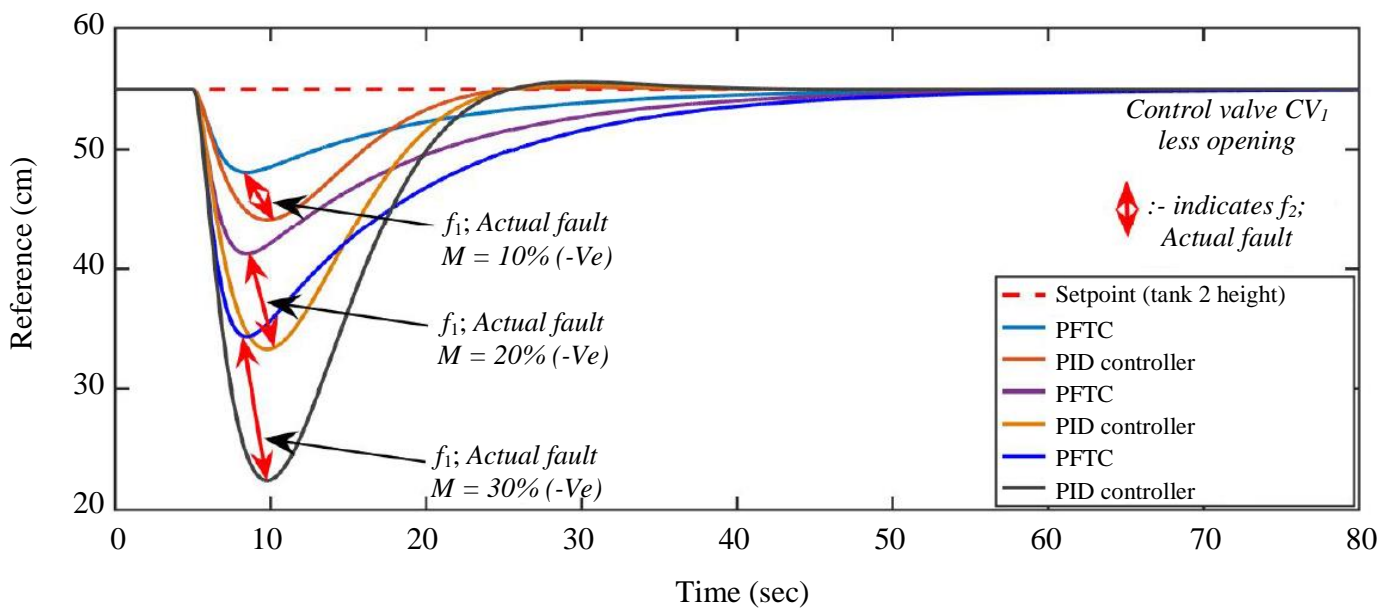

Fig. 7: TTCNILCS height response with different magnitude of actuator fault

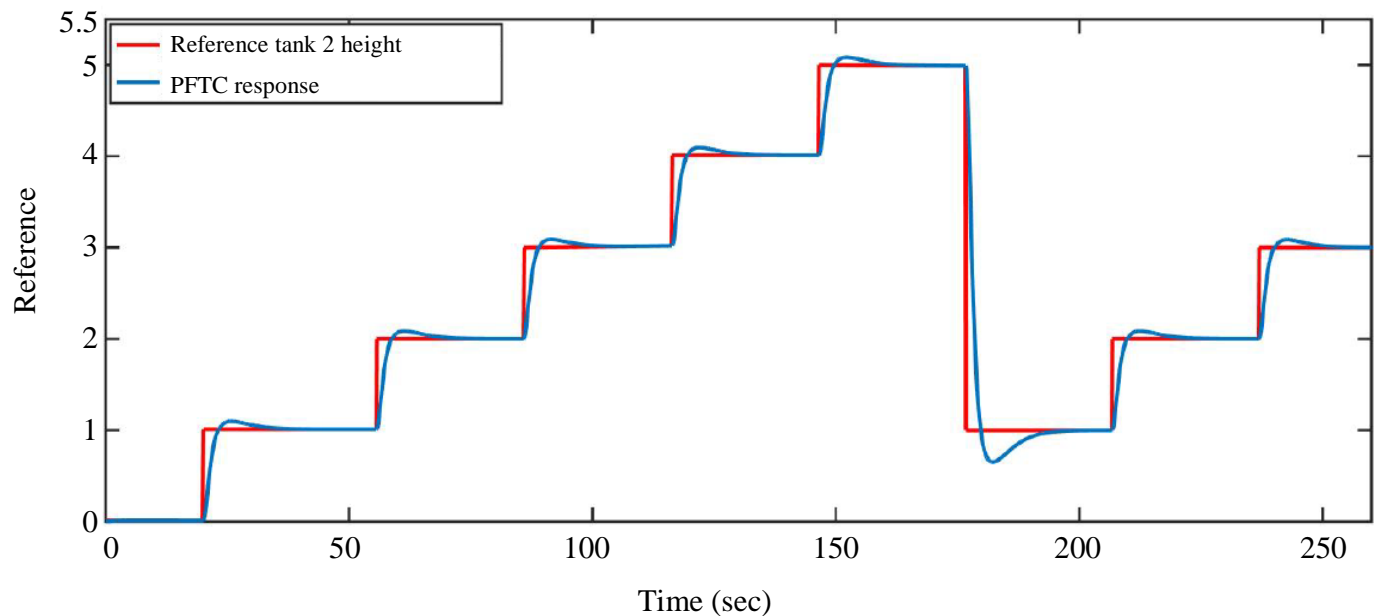

Fig. 8: PFTC Tracking control with variable step change trajectory 
Himanshukumar R. Patel and Vipul A. Shah / Journal of Mathematics and Statistics 2020, Volume 16: 35.46 DOI: $10.3844 /$ jmssp.2020.35.46

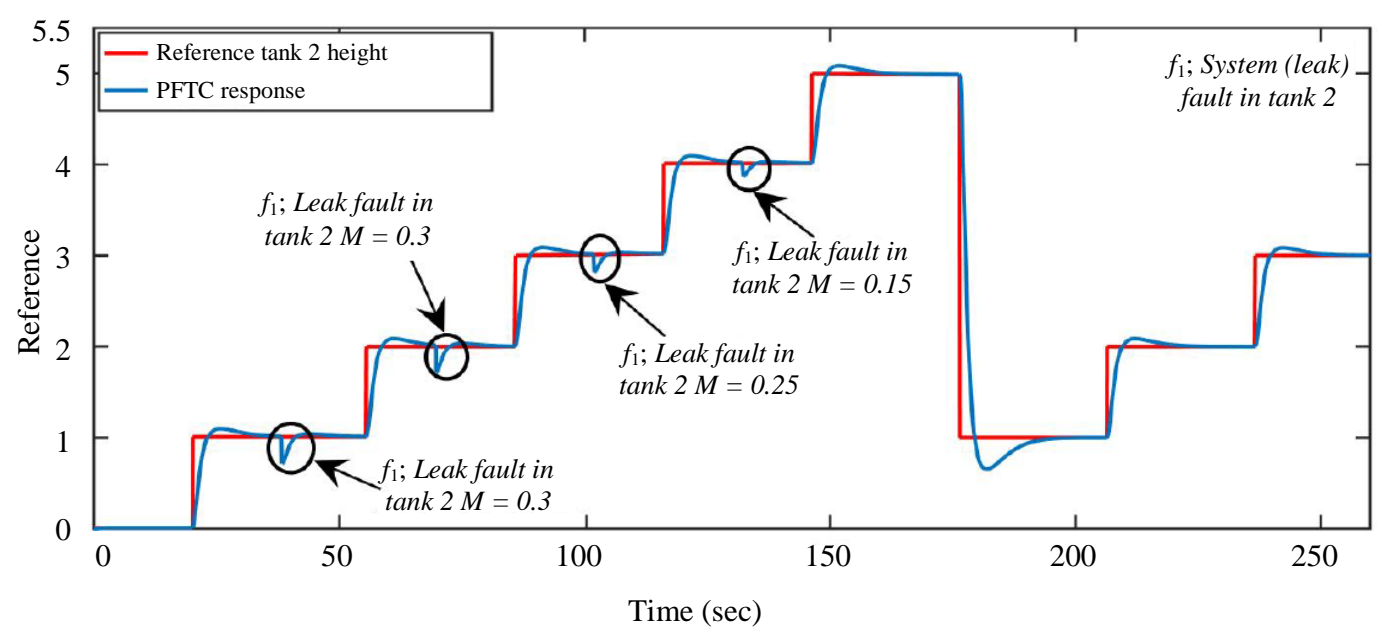

Fig. 9: PFTC Tracking control with variable step change trajectory system fault

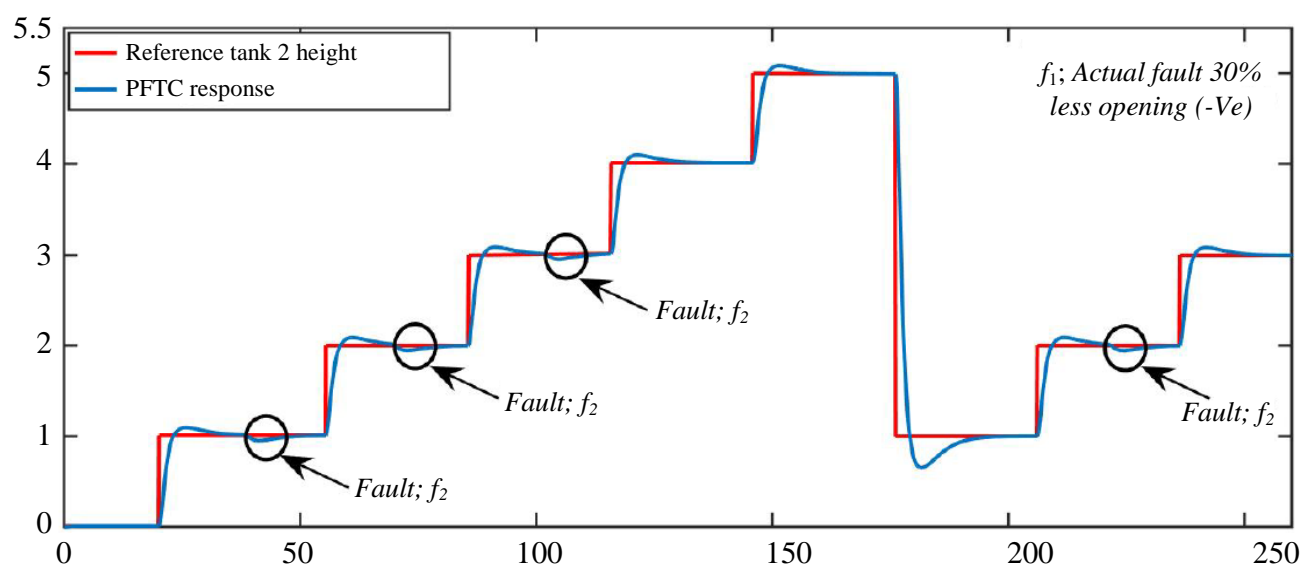

Fig. 10: PFTC Tracking control with variable step change trajectory actuator fault

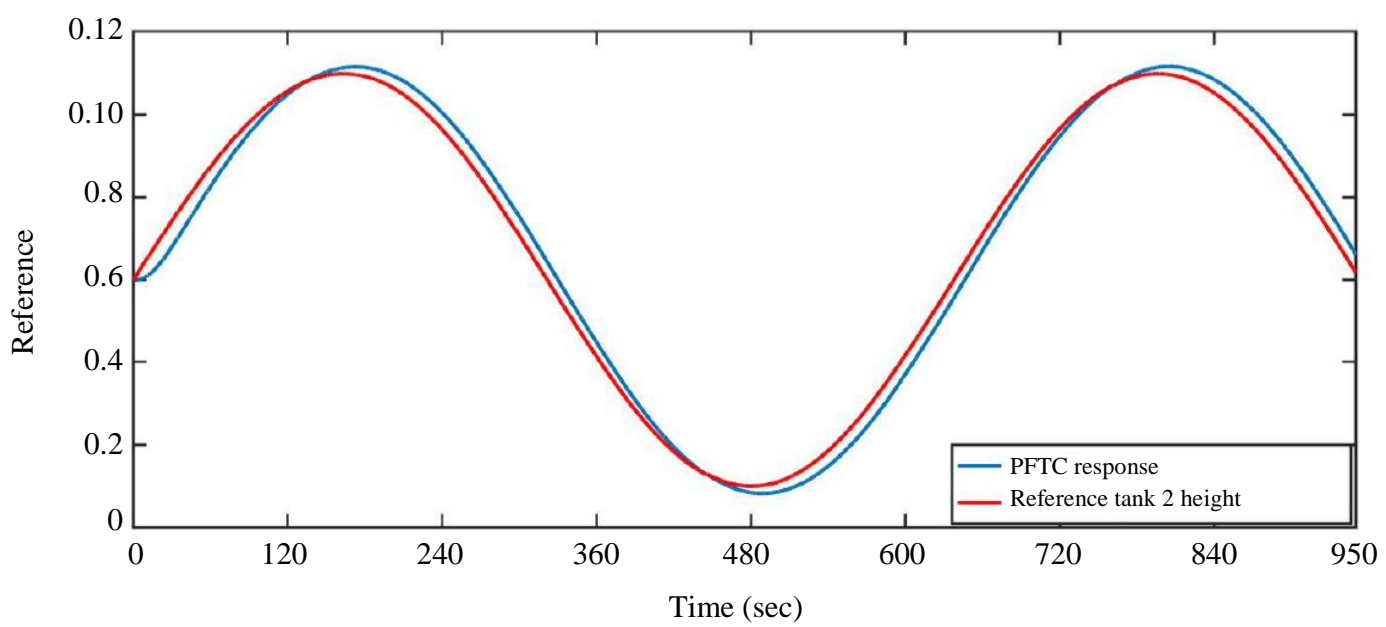

Fig. 11: PFTC Tracking control with variable step change trajectory 


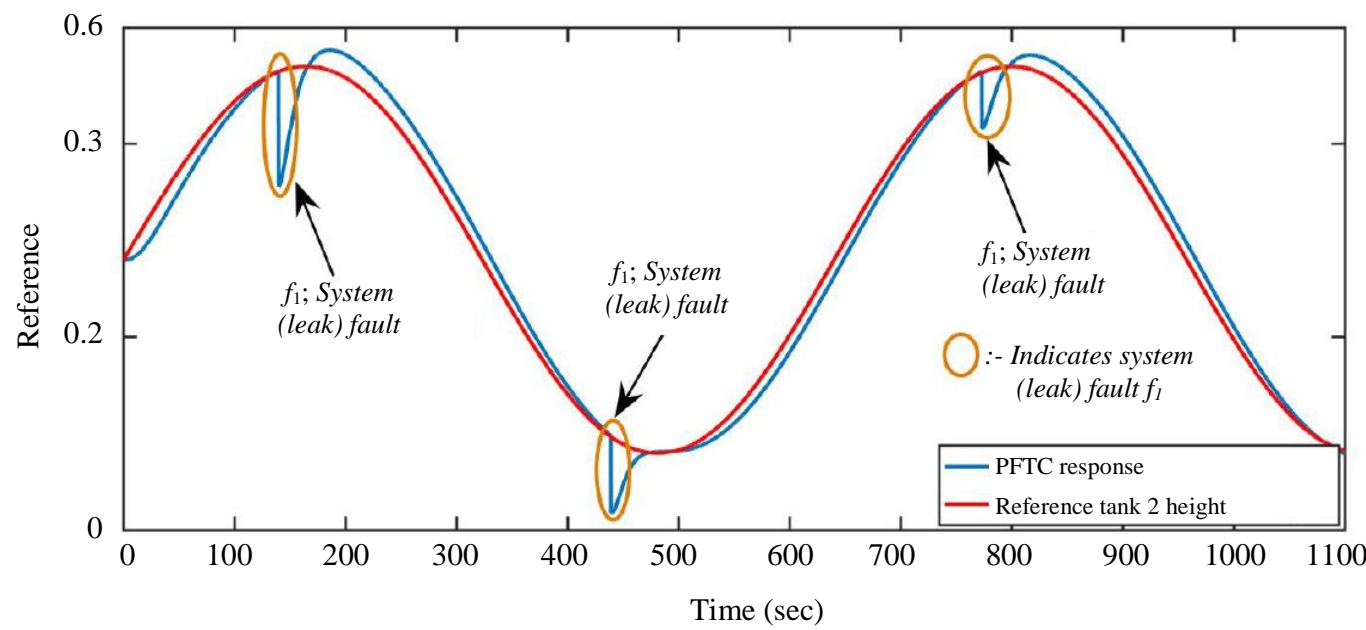

Fig. 12: PFTC Tracking control with variable step change trajectory system fault

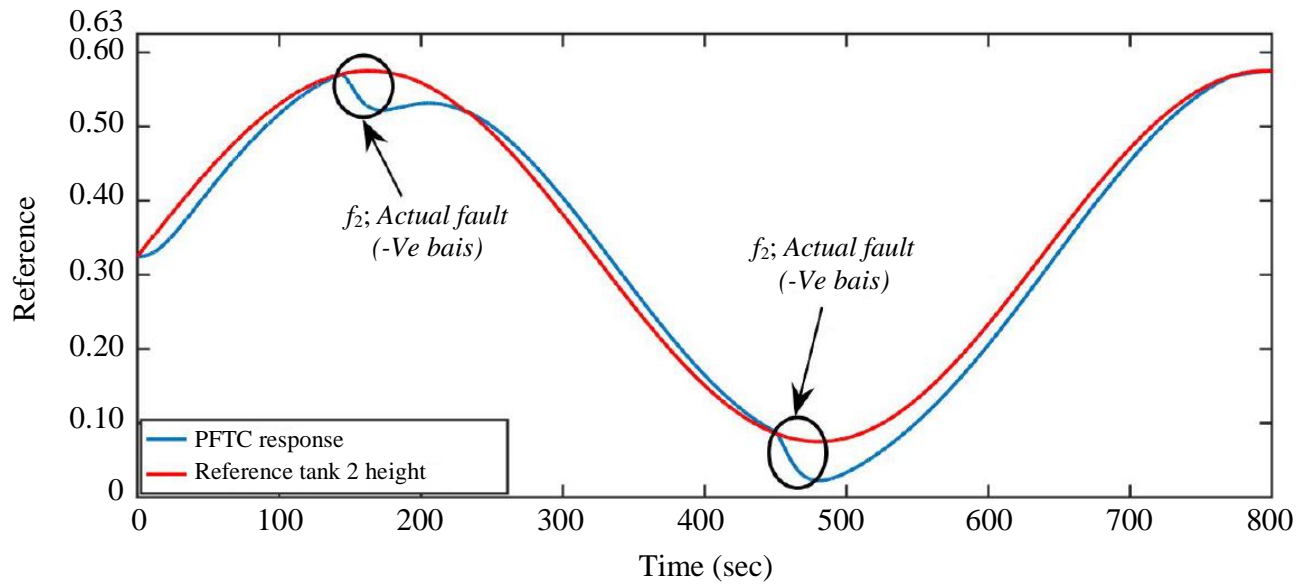

Fig. 13: PFTC Tracking control with variable step change trajectory actuator fault

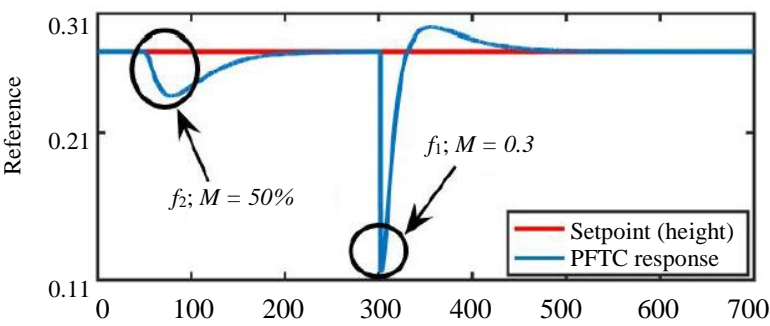

(a)

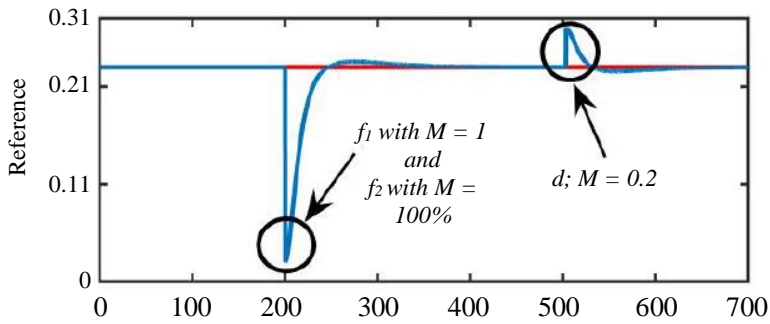

(c)

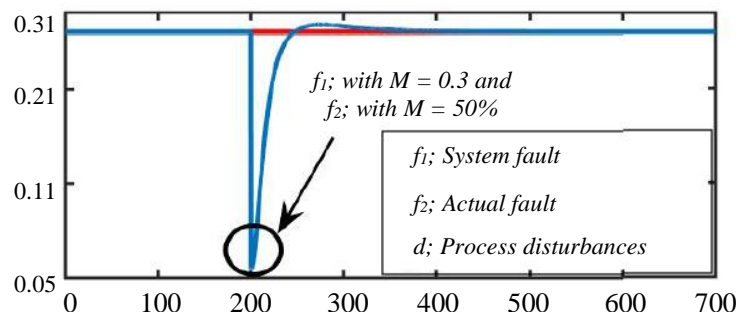

(b)

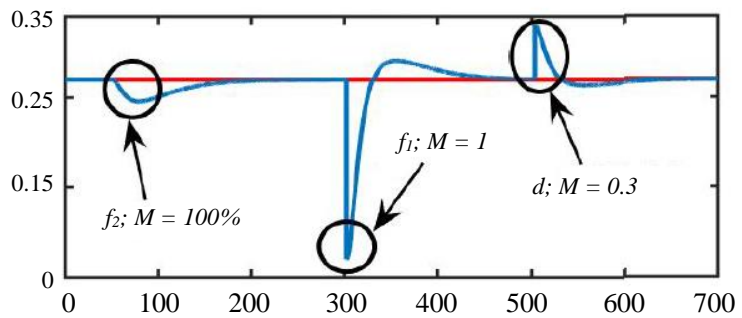

(d)

Fig. 14: TTCNILCS height response with two faults and process disturbances constraints 
Table 2: Demographics of the fault scenario with magnitude values

\begin{tabular}{lll}
\hline Sr. No. & Faults type & Failure details \\
\hline 1. & System Component (leak) $f_{1}$ & Tank 2 Leak at bottom \\
& & 1. Leak fault $\mathrm{M}=10 \%$ \\
& 2. Leak fault $\mathrm{M}=20 \%$ \\
& 3. Leak fault $\mathrm{M}=30 \%$ \\
2. & Control valve $\left(C V_{1}\right)$ opening with error \\
& Actuator $f_{2}$ & 1. Actuator fault $\mathrm{M}=10 \%(-\mathrm{Ve})$ \\
& 2. Actuator fault $\mathrm{M}=20 \%(-\mathrm{Ve})$ \\
& 3. Actuator fault $\mathrm{M}=30 \%(-\mathrm{Ve})$ \\
\hline
\end{tabular}

Table 3: Error response of TTCNILCS with system faults

\begin{tabular}{lllll}
\hline Controller & $f_{1}$ & ISE & ITSE & MSE \\
\hline PFTC & $\mathrm{M}=10 \%$ & $1.693 \mathrm{e}+2$ & $2.189 \mathrm{e}+2$ & 0.1891 \\
PID & & $2.579 \mathrm{e}+2$ & $3.914 \mathrm{e}+2$ & 0.4113 \\
PFTC & $\mathrm{M}=20 \%$ & $4.199 \mathrm{e}+2$ & $7.472 \mathrm{e}+2$ & 0.7314 \\
PID & & $5.258 \mathrm{e}+2$ & $2.386 \mathrm{e}+3$ & 2.3585 \\
PFTC & $\mathrm{M}=30 \%$ & $6.128 \mathrm{e}+2$ & $2.545 \mathrm{e}+3$ & 1.6296 \\
PID & & $7.358 \mathrm{e}+2$ & $3.999 \mathrm{e}+3$ & 3.8369 \\
\hline
\end{tabular}

Table 4: Error response of TTCNILCS with actuator fault

\begin{tabular}{lllll}
\hline Controller & $f_{2}$ & ISE & ITSE & MSE \\
\hline PFTC & $\mathrm{M}=10 \%$ & $1.999 \mathrm{e}+2$ & $1.593 \mathrm{e}+2$ & 0.1586 \\
PID & & $2.079 \mathrm{e}+2$ & $3.214 \mathrm{e}+2$ & 0.3196 \\
PFTC & $\mathrm{M}=20 \%$ & $3.999 \mathrm{e}+2$ & $6.372 \mathrm{e}+2$ & 0.6344 \\
PID & & $4.158 \mathrm{e}+2$ & $1.286 \mathrm{e}+3$ & 1.2785 \\
PFTC & $\mathrm{M}=30 \%$ & $5.998 \mathrm{e}+2$ & $1.434 \mathrm{e}+3$ & 1.4273 \\
PID & & $6.236 \mathrm{e}+2$ & $2.893 \mathrm{e}+3$ & 2.8766 \\
\hline
\end{tabular}

Table 5: Error response of TTCNILCS for PFTCS robustness test

\begin{tabular}{|c|c|c|c|c|c|c|}
\hline $\begin{array}{l}\text { Frequency of fault } \\
\text { Occurrence }\end{array}$ & $f_{1}$ & $f_{2}$ & d & ISE & ITSE & MSE \\
\hline Different time & $\mathrm{M}=30 \%$ & $M=50 \%$ & NA & 9.74229 & $1.0023 \mathrm{e}+2$ & 0.0014 \\
\hline Same time & $\mathrm{M}=30 \%$ & $M=50 \%$ & NA & $2.4618 \mathrm{e}+1$ & $8.7083 e+1$ & 0.0035 \\
\hline Same time & $M=100 \%$ & $M=100 \%$ & $\mathrm{M}=0.2$ & $1.0206 \mathrm{e}+2$ & $2.1358 \mathrm{e}+2$ & 0.0145 \\
\hline Different time & $\mathrm{M}=1000 \%$ & $M=100 \%$ & $\mathrm{M}=0.3$ & $1.0465 \mathrm{e}+2$ & $3.3831 \mathrm{e}+2$ & 0.0149 \\
\hline
\end{tabular}

\section{Conclusion}

In this work we proposed PFTC strategy using hybrid controller for TTCNILCS nonlinear process system and implemented subject to system and actuator faults. Proposed PFTC is successfully designed and implemented to provide effective control solutions (i.e., tracking control, stabilizing control, disturbance minimization control, with two faults and process disturbances etc.) for the TTCNILCS. All four possible solutions of PFTC encountered and found satisfactory response when system and actuator fault occurs in the system.

\section{Acknowledgement}

Above research work is a part of the Part-time $\mathrm{Ph} . \mathrm{D}$. in Instrumentation and Control Engineering Department, Dharmsinh Desai University. Research work carried out in Instrumentation and Process Control (IPC) Laboratory at Chemical Engineering department and simulation laboratory in Instrumentation and Control Engineering Department, Dharmsinh Desai University.

\section{Funding Information}

This research received no external and internal funding.

\section{Author's Contributions}

Himanshukumar R. Patel: Conceptualization, methodology, software, validation, formal analysis, investigation and writing-original draft preparation.

Vipul A. Shah: Conceptualization, writing-review and editing and Supervision.

\section{Ethics}

There is no ethical issue involved in this article, as it is original contribution of the author. 


\section{References}

Altinisik, U. and M. Yildirim, 2012. A new fault tolerant control approach for the three-tank system using data mining. J. Comput. Electrical Eng., 38: 1627-1635. DOI: 10.1016/j.compeleceng.2012.06.011

Basin, M., L. Li, M. Krueger and S.X. Ding, 2015. A finite-time-convergent fault-tolerant control and its experimental verification for DTS200 three-tank system. Proceedings of the International Workshop on Recent Advances in Sliding Modes, Apr. 9-11, IEEE Xplore Press, Istanbul, Turkey, pp: 1-6.

DOI: 10.1109/RASM.2015.7154633

Buciakowski, M., M. de Rozprza-Faygel, J. Ochalek and M. Witczak, 2014. Actuator fault diagnosis and fault-tolerant control: Application to the quadrupletank process. J. Phys., 570: 082002-082002.

Capiluppi, M. and A. Paoli, 2005. Distributed fault tolerant control of the two-tank system benchmark. Proceedings of the 44th IEEE Conference on Decision and Control, Dec. 15-15, IEEE Xplore Press, Seville, Spain, pp: 7674-7679.

DOI: 10.1109/CDC.2005.1583401

Du, M., 2012. Fault diagnosis and fault-tolerant control of chemical process systems. Ph.D. Thesis, Department of Chemical Engineering, McMaster University, Hamilton, Ontario.

Dorf, R. and R. Bishop, 2011. Modern Control Systems. 12th Edn., Prentice Hall, Pearson Education, New Jersey.

Frank, P.M., 2004. Trends in fault-tolerant control of engineering systems. IFAC Proc., 37: 377-384.

DOI: $10.1016 /$ S1474-6670(17)31053-4

Isermann, R. and P. Balle, 1997. Trends in the application of model-based fault detection and diagnosis of technical processes. Control Theory Pract., 5: 709-719.

DOI: $10.1016 /$ S0967-0661(97)00053-1

Jiang, J. and X. Yu, 2012. Fault-tolerant control systems: A comparative study between active and passive approaches. Annual Rev. Control, 36: 60-72.

DOI: 10.1016/j.arcontrol.2012.03.005

Jiang, J. and Y. Zhang, 2003. Fault diagnosis and reconfigurable control of a pressurizer in a nuclear power plant. IFAC Proc., 6: 993-998.

DOI: $10.1016 /$ S1474-6670(17)36622-3

Maruthai, S., G.J. Srinivasan, R.R. Hemamalini, 2009. Integrated fuzzy logic based intelligent control of three tank system. Serbian J. Electrical Eng., 6: 1-14. DOI: $10.2298 /$ sjee0901001s

Noura, H., D. Theilliol and D. Sauter, 2000. Actuator fault-tolerant control design: Demonstration on a three-tank-system. Int. J. Syst. Sci., 31: 1143-1155. DOI: $10.1080 / 002077200418414$
Patel, H. and V. Shah, 2020. Fault Tolerant Control Using Interval Type-2 Takagi-Sugeno Fuzzy Controller for Nonlinear System. In: Intelligent Systems Design and Applications, Abraham, A., A. Cherukuri, P. Melin, N. Gandhi (Eds.), Springer, Cham, pp: 150-164.

Patel, H.R. and V.A. Shah, 2019a. A passive fault tolerant control strategy for a non-linear system: An application to the two tank conical non-interacting level control system. MASKAY, 9: 1-8. DOI: $10.24133 /$ maskay.v9i1.1094

Patel, H.R. and V.A. Shah, 2019b. Performance comparison of passive fault tolerant control strategy with PI and fuzzy control of single-tank level process with sensor and system fault. Am. J. Eng. Applied Sci.

Patel, H.R. and V.A. Shah, 2019c. Passive fault tolerant control system for two-tank interacting conical level control system against partial actuator failures. J. Comput. Sci.

Patel, H.R. and V.A. Shah, 2019d. A fault-tolerant control strategy for non-linear system: An application to the two tank Conical non interacting level control system. Proceedings of the IEEE Distributed Computing, VLSI, Electrical Circuits and Robotics, Aug. 13-14, IEEE Xplore Press, Mangalore (Mangaluru), India.

DOI: 10.1109/DISCOVER.2018.8674119

Patel, H.R. and V.A. Shah, 2019e. Actuator and system component fault tolerant control using interval type2 Takagi-Sugeno fuzzy controller for hybrid nonlinear process. Int. J. Hybrid Intell. Syst.

Patel, H.R. and V.A. Shah, 2018a. Fault tolerant control systems: A passive approaches for single tank level control system. J. Instrument. Control Eng., 6: 11-18. DOI: $10.26634 /$ jic.6.1.13934

Patel, H.R. and V.A. Shah, 2018b. Fuzzy logic based passive fault tolerant control strategy for a singletank system with system fault and process disturbances. Proceedings of the 5th International Conference on Electrical and Electronics Engineering, May 3-5, Istanbul, Turkey, pp: 257-262. DOI: 10.1109/ICEEE2.2018.8391342

Patel, H.R. and V.A. Shah, 2018c. Fault detection and diagnosis methods in power generation plantsIndian power generation sector perspective: An introductory review. J. Energy Manage., 2: 31-50.

Patel, H.R. and V.A. Shah, 2018d. A framework for fault-tolerant control for an interacting and noninteracting level control system using AI. Proceedings of the 15th International Conference on Informatics in Control, Automation and Robotics, (CAR' 18), SCITEPRESS - Science and Technology Publications, Lda., pp: 180-190. DOI: $10.5220 / 0006862001900200$ 
Parikh, N., S, Rathore, R. Misra and A. Markana, 2017. A comparison between NMPC and LQG for the level control of three tank interacting system. Proceedings of the Indian Control Conference, Jan. 4-6, IEEE Xplore Press, Guwahati, India, pp: 200-205.

DOI: $10.1109 /$ INDIANCC.2017.7846475

Shamily, S., Praveena and N.S. Bhuvaneswari, 2015. Intelligent control and adaptive control for interacting system. Proceedings of the IEEE Technological Innovation in ICT for Agriculture and Rural Development, Jul. 10-12, IEEE Xplore Press, Chennai, India, pp: 116-121.

DOI: 10.1109/TIAR.2015.7358542

Tian, F., 2015. A hybrid controller for stability robustness, performance robustness and disturbance attenuation of a MAGLEV system. Ph.D. Dissertation, Marquette University.

Torres, C.M., L. Lavigne, F. Cazaurang, E.A. Garcia and D.D. Romero, 2013. Fault tolerant control of a three tank system: A flatness based approach. Proceedings of the Conference on Control and Fault-Tolerant Systems, Oct. 9-11, IEEE Xplore Press, Nice, France, pp: 529-534. DOI: 10.1109/SysTol.2013.6693908
Villani, M., M. Tursini, G. Fabri and L. Castellini, 2010. Fault-tolerant PM brushless DC drive for aerospace application. Proceedings of the 19th International Conference on Electrical Machines, Sept. 6-8, IEEE Xplore Press, Rome, Italy, pp: 1-7.

DOI: 10.1109/ICELMACH.2010.5608295

Wayne and B. Bequette, 2003. Process Control Modeling, Design and Simulation. Prentice Hall, USA.

Wayne and B. Bequette, 1991. Nonlinear predictive control using multi-rate sampling. Canad. J. Chem. Eng., 69: 136-143. DOI: 10.1002/cjce.5450690116 